Article

\title{
Sustainability of the Jeju Haenyeo Fisheries System in the Context of Globally Important Agricultural Heritage System (GIAHS)
}

\author{
Wonseob Song \\ Department of Geography Education, College of Education, Jeonbuk National University, 567, Baekje-daero, \\ Deokjin-gu, Jeonju-si, Jeollabuk-do 54896, Korea; wssong@jbnu.ac.kr
}

Received: 26 February 2020; Accepted: 23 April 2020; Published: 25 April 2020

check for updates

\begin{abstract}
According to the Brundtland Report of the World Commission on Environment and Development (WCED), the concept of sustainability emerges from the expectation of development that meets the needs of the present without compromising the ability of future generations to meet their own needs. This notion of sustainability is highly related to the implication of the Globally Important Agricultural Heritage System (GIAHS) of the Food and Agriculture Organization (FAO). The haenyeo (women divers) fisheries system of Jeju Island, South Korea, serves as an empirical case that illustrates that the core meaning of GIAHS is placed on the concept of sustainability. The most important objective of this case study is to explore how the five main values of GIAHS-(i) food and livelihood security, (ii) agro-biodiversity, (iii) local and traditional knowledge systems, (iv) cultures, value systems, and social organizations, and (v) landscape and seascape features-can be interlocked, and how the concept of sustainability can emerge through this interlocked relationship. In doing this, the value of both GIAHS and the Jeju haenyeo fisheries system is illuminated.
\end{abstract}

Keywords: sustainability; GIAHS; Jeju haenyeo fisheries system; landscape

\section{Introduction}

The main purpose of this paper is to reveal the meaning of sustainability in the haenyeo (women divers) fisheries system of Jeju Island, South Korea, in the context of the Globally Important Agricultural Heritage System (GIAHS) of the Food and Agriculture Organization (FAO). First, the meaning of sustainability in the Jeju haenyeo fisheries system is "the capacity for continuance into the long-term future" [1] of the Jeju haenyeo fisheries system. Second, the context of GIAHS is indicated by the five main values of GIAHS: (i) food and livelihood security, (ii) agro-biodiversity, (iii) local and traditional knowledge systems, (iv) cultures, value systems, and social organizations, and (v) landscape and seascape features [2].

In Jeju Island, South Korea (see the left-hand photo of Figure 1 for the location of Jeju Island), haenyeo are professional female divers who dive to the bottom of the sea to catch seafood without an underwater breathing apparatus. The Jeju haenyeo fisheries, or the sea-diving industry on Jeju, emerged as islanders turned to the abundant marine resources found on the rocky seafloor in an attempt to compensate for a constant shortage of agricultural products due to the poor soil on the volcanic island.

The haenyeo fisheries on Jeju are carried out in 102 fishing villages along the coasts of the island (in the right-hand photos of Figure 1). The Jeju haenyeo fisheries system geographically covers fishing grounds within a distance of $1.5 \mathrm{~km}$ from the coastline and a depth of $7 \mathrm{~m}$ at low tide, as well as the land area of the 102 fishing villages, which accounts for a total of 71,563 hectares (see the red belt in the right-hand photos of Figure 1). Haenyeo gather nine major marine products in total: Hizikia fusiformis, Gelidium amansii, Eklonia cava, Undaria pinnatifida, Apostichopus japonicas, Anthocidaris crassispina, Turbo sazae, Haliotis discus hanai, and Haliotis diversicolor (see Figure 2 for details). 


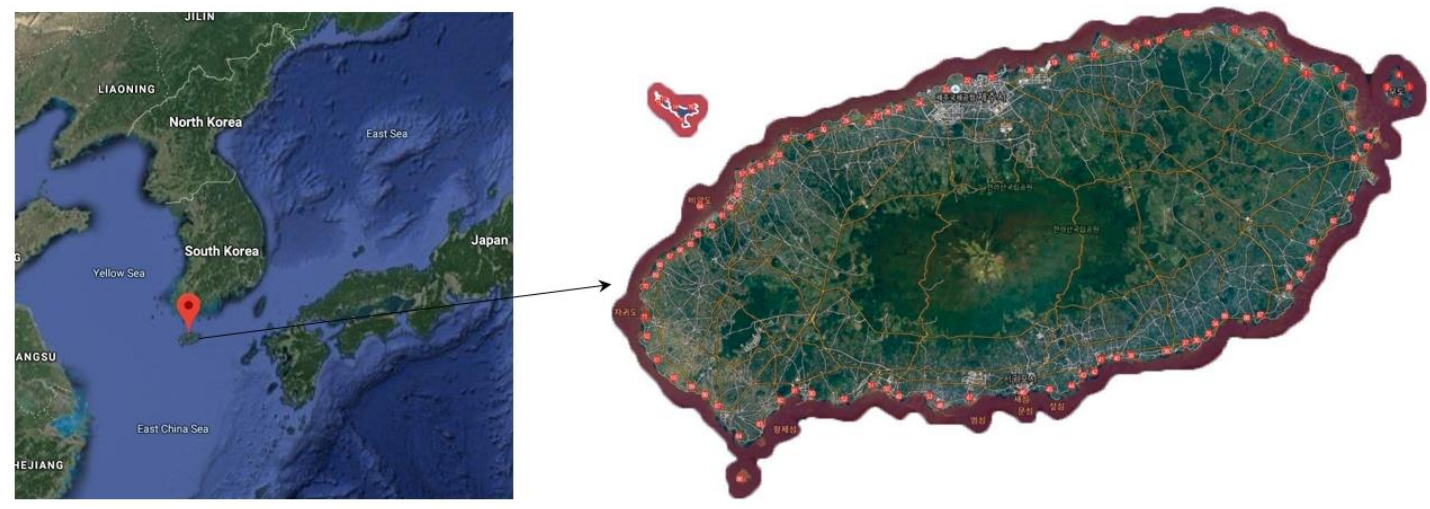

Figure 1. Location of Jeju Island, South Korea.

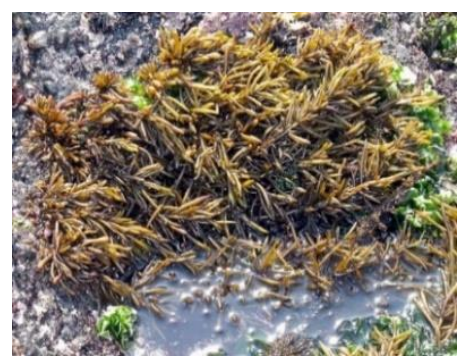

Hizikia fusiformis

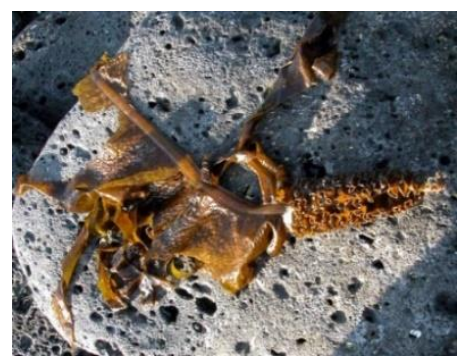

Undaria pinnatifida

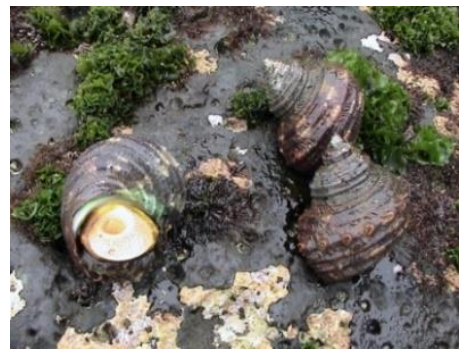

Turbo sazae

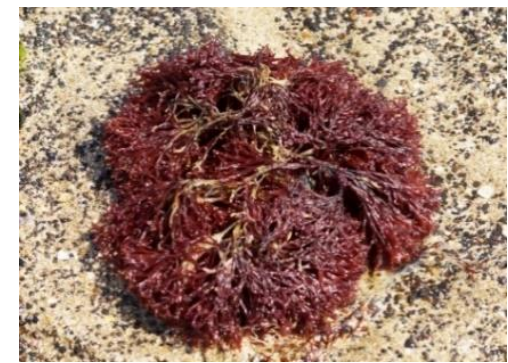

Gelidium amansii

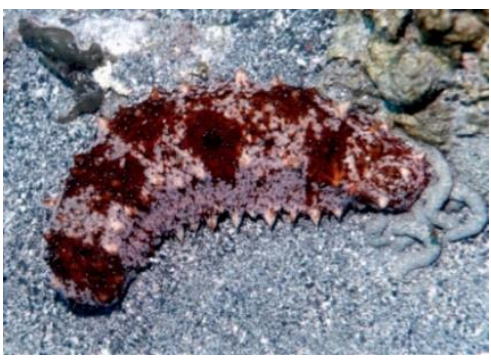

Apostichopus japonicas

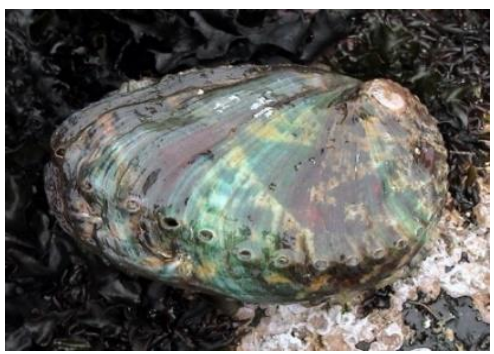

Haliotis discus hanai

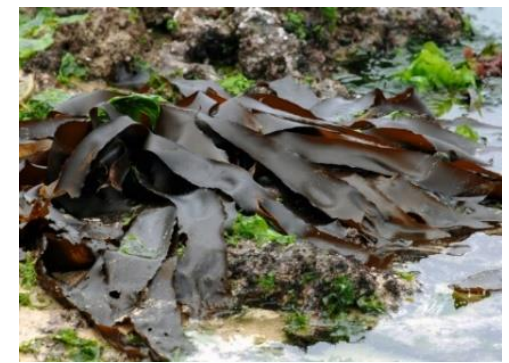

Eklonia cava

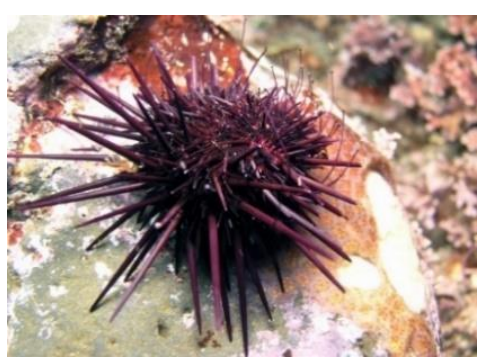

Anthocidaris crassispina

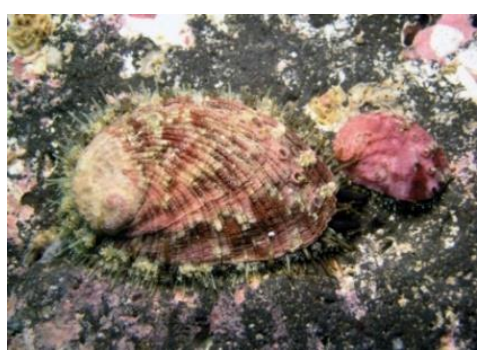

Haliotis diversicolor

Figure 2. Seafood that the Jeju haenyeo usually harvest (Photo: Choi, Kwang-Sik at Jeju National University of South Korea).

Jeju haenyeo use these marine products to create various dishes, and the dishes cooked with the products harvested by haenyeo have been the main part of meals for the people of Jeju since ancient times. The Jeju haenyeo fisheries system has made it possible to secure a livelihood not only at the household level but also at the local economy level. Among the legends of the chart in Figure 3, "village fisheries" are, in fact, the haenyeo fisheries. The village fisheries account for as little as $10 \%$ of 
the total fishery production on Jeju (Figure 3). Nonetheless, as of 2017, the haenyeo fisheries produce about $90 \%$ of all shellfish exported from the island, showing that the local sea-diving industry has been the driving force of the local economy (see Figure 4).
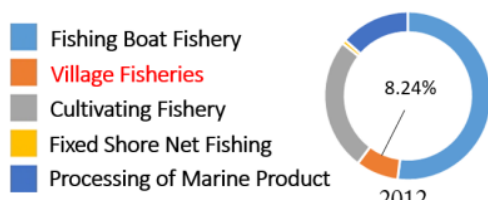

2012

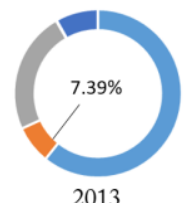

2013

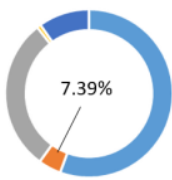

2014

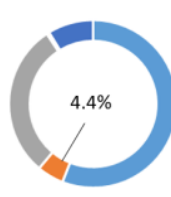

2015

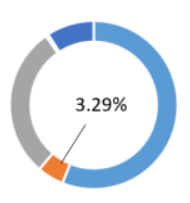

2016

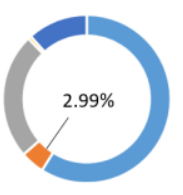

2017

Figure 3. Percentage of fishery production volume and village fisheries in the Jeju area.

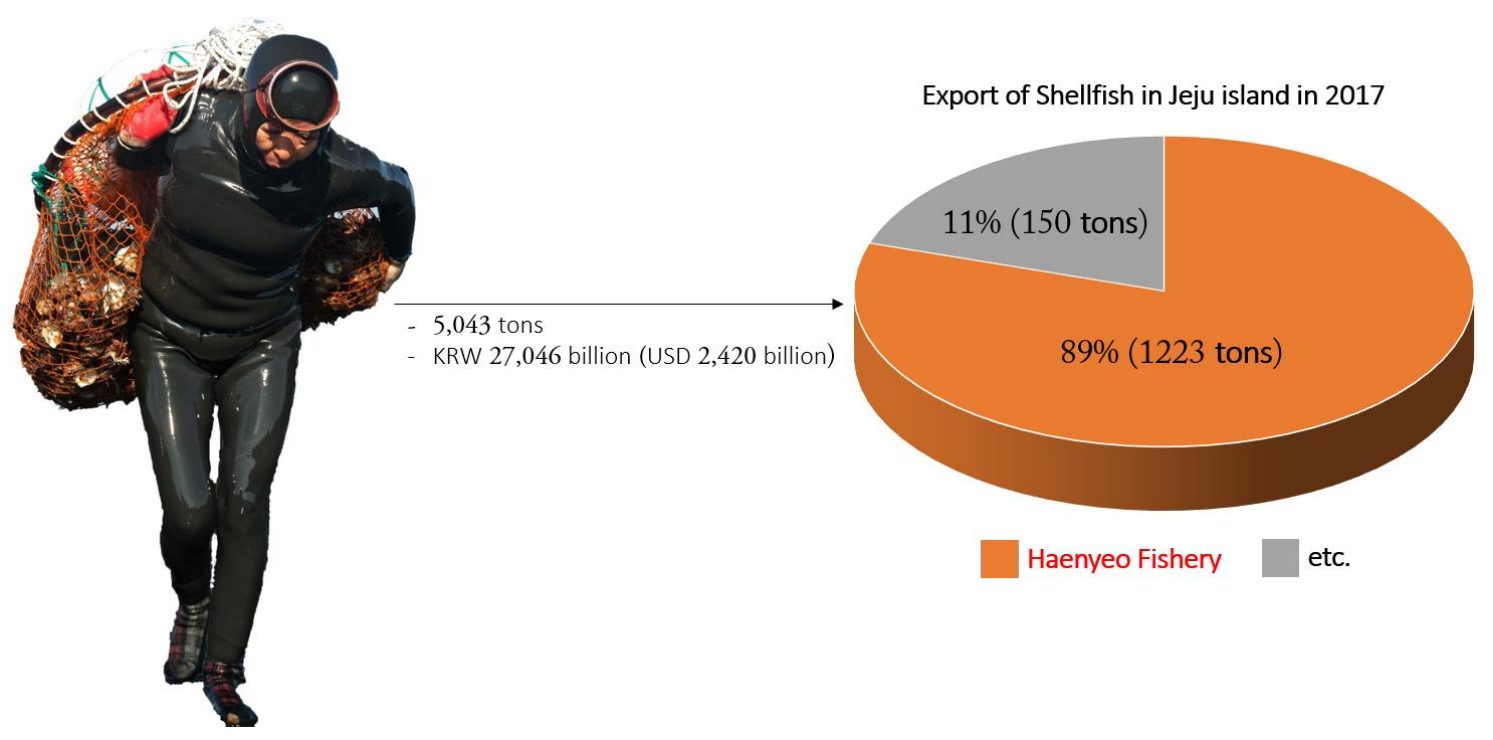

Figure 4. Jeju haenyeo fishery production in 2017.

Until now, many of the local studies on Jeju haenyeo fisheries have focused only on the superficial values of Jeju haenyeo culture. For example, it is strongly believed that all of the values of the Jeju haenyeo fisheries can be found in the water clothes, shamanistic rituals, and folk songs of Jeju haenyeo [3-5]. This means that many local studies on Jeju haenyeo culture give only a "thin description" of Jeju haenyeo culture. According to a prominent anthropologist, Clifford Geertz, there are two layers of a socio-cultural phenomenon [6]. The first is the superficial phenomenon, and the second is its hidden socio-cultural codes. Depictive observation of the socio-cultural phenomenon refers to the thin description, and semantic analysis of it refers to the thick description (ibid). To achieve a "thick description" of Jeju haenyeo fisheries, the sustainability of the Jeju haenyeo fisheries system is explored through the five main values of GIAHS. Considering the problematic concern in the previous studies on the Jeju haenyeo fisheries, the body of the present paper focuses on the analysis of the Jeju haenyeo fisheries through the five main values of GIAHS.

To do this, the body of the present papers consists of four sub-sections. In the first part, "food and livelihood security", it is demonstrated that the Jeju haenyeo fisheries system does much more than just help secure food; it also plays a huge role in securing livelihoods for individual haenyeo households and the local economy at large. The second part, agro-biodiversity and traditional knowledge systems, is relevant to the sustainable supply of marine products that secure a livelihood for individual haenyeo households and the local economy at large. The third part-cultures, value systems, and social organizations-is highly linked to the socio-political mechanism in Jeju haenyeo culture, in which the co-relationship between agro-biodiversity and the traditional knowledge system can be maintained without "the tragedy of the commons" [7]. The fourth part, landscape and seascape features, shows the material culture (the folk housing landscape of the Jeju haenyeo), which resonates in the fourth 
section. In the concluding chapter, on the basis of the implication in the body of the present paper, the direction of local policies regarding the conservation and management of the Jeju haenyeo fisheries system is suggested.

\section{Looking at Jeju Haenyeo Fisheries through GIAHS}

Looking through the lens of GIAHS, the Jeju haenyeo fisheries consist of five main pillars. Here, it must be highlighted that, in the Jeju haenyeo fisheries, the five main pillars are all interlocked together. As shown above, the reciprocal relationship amongst the five pillars of the landscape of the Jeju haenyeo fisheries starts from (i) food and livelihood security, goes through (ii) agro-biodiversity, (iii) local and traditional knowledge systems, and (iv) cultures, value systems, and social organizations, and ends in (v) landscape and seascape features [8].

\subsection{Food and Livelihood Security}

The food and livelihood of Jeju haenyeo have been secured by gathering marine products. The major marine products are nine in total: Hizikia fusiformis, Gelidium amansii, Eklonia cava, Undaria pinnatifida, Apostichopus japonicas, Anthocidaris crassispina, Turbo sazae, Haliotis discus hanai, and Haliotis diversicolor. The economic value of the marine products that Jeju haenyeo usually harvested rapidly increased in the early twentieth century. The main cause of the increase in the economic value of this seafood can be found in its exchange value. Jeju Island is a volcanic island, formed from a volcanic explosion. Jeju Island's soil is composed of volcanic ash soil (soil consisting of volcanic ash). Jeju Islanders call fields formed from volcanic ash soil tteunttang or tteunbat. This natural geographical environment makes the land of Jeju Island infertile [9].

The average annual precipitation in the coastal region of Jeju Island is $1568 \mathrm{~mm}$, and, in the mountainous area of Mt. Hallasan, as much as $3000 \mathrm{~mm}$ falls as orographic rainfall. If this is averaged, it is $1918 \mathrm{~mm}$ (South Korea's average is $960 \mathrm{~mm}$, the world average is $743 \mathrm{~mm}$ ), making it the area with the highest precipitation in Korea. Despite this, Jeju is made up of clay loam soil (clay content is $37.5 \%-50 \%$ ), which is called "thick soil" (mud soil). Thus, except for a few areas in which soil with retention capacity is distributed, most areas become dry, and rice farming is not possible (ibid).

This lack of surface water retention is not only caused by the volcanic ash soil but also because of the topographical form of a shield volcano (aspite volcano), which is shaped like a shield placed upside down. This means that Jeju Island has little flat land. Thus, when it rains, the rainwater leaks into the sea through gareria (the Jeju dialect equivalent of wadi, which is like a dry riverbed where water only flows when it rains in the dry desert climate zone (BW climate)) quickly because of the short runoff distance, and thus, it is difficult for water to be retained. This lack of surface water is inevitably unfavorable for agriculture (ibid). The harsh soil of Jeju Island does not allow Jeju Islanders to get enough agricultural crops to exchange for other products. In other words, almost all of the agricultural crops are consumed only for their food.

Unlike agricultural crops harvested from fields, large amounts of marine products harvested from the sea are used for sale. That is, for Jeju haenyeo, marine products are the most important cash cow. The following study of Takahashi, which is a typical portrait of the haenyeo's household economy, specifically shows that the income of haenyeo in the individual household economy is a critical conduit through which the Jeju haenyeo earn money [10]. According to his study, in the household economy of Jeju Island, cultural expenses, especially education expenses, some energy expenses, clothing expenses, taxes, and other expenses, which are essential for cash consumption, are accounted for by cash collected from the marine products harvested by the haenyeo (ibid).

Considering the marine products harvested from the sea to be a cash cow, one of the Jeju haenyeo wrote of her experience:

I had nothing, learned nothing, and couldn't do business, either, but I knew how to dive into the water and catch seafood. And the only thing you need for muljil is sojungi (haenyeo's 
traditional diving suit). For farming, you need to buy seeds and get fertilizer, but muljil was nothing like that. Because I knew how to dive at least, I could feed my kids and get clothes for them. My kids have never been embarrassed by me being haenyeo. Instead, they appreciate the work I do, so I'm proud of my profession.

(Interviewee: Song-Hwan Ko/Interview source: Jeju Haenyeo Museum)

Additionally, the seafood that the Jeju haenyeo harvest are very important for their dietary life and nutrition. Haenyo make their own food from the marine products they gather from the sea. They sell these goods for merchandising and made their own food, mainly using flawed shellfish or less popular marine plants. Although simple, the vigorous gathering activity of the haenyo, despite the heavy energy consumption it brings, is supported by the food that the haenyo have, which is made from fresh ingredients filled with rich nutrition. The reason that the haenyo's gathering work could last for such a long time is because the marine products gathered by the haenyo are just as valuable [11].

The same goes for the reason that the haenyo's dietary life is essential; if nobody processed the ingredients into food, their value as food would be lost. The Jeju haenyo, who have regarded the sea as their base for living, proactively use the ecosystem of marine plants around the coast of volcanic rocks at which various ocean currents meet. Their improvised method of mixing marine plants into staples to resist famine in bad years eventually turned out to be valuable knowledge for decent nutritional intake. Even now, this food culture and folklore knowledge continues to be transferred in order to foster sustainable trends in modern food culture (ibid).

\subsection{Agro-Biodiversity and Traditional Knowledge System}

The reason that Jeju haenyeo could achieve food and livelihood security consistently is that the agro-biodiversity of the seafood that Jeju haenyeo harvest can be maintained. It seems that the "ecological niche" of the seafood of the Jeju haenyeo could be an effective way of expressing the meaning of the agro-biodiversity of the seafood. An American ecologist, Frank H. Heppner, related this to the notion of an ecological niche:

If a habitat is a street address, a niche is like a job description. An organism has a huge number of individual relationships with other organisms in its vicinity. If it is a predator, it has a relationship with the prey species-If the prey species should go extinct, the predator is in deep trouble ... Most of these relationships are mutual. Prey affect predators, and predators affect prey ... The sum of all the relationships in an organism's existence is its niche in life. The word niche in ordinary English means a 'little hollow place in a wall where you can put something, like a statue,' so ecological niche is the little place where an organism fits in the general scheme of things [12].

Each of the nine species that Jeju haenyeo harvest has its own ecological niche, and all of them interconnect with each other (Figure 2). The harvested seafood for Jeju haenyeo comprises nine species, which are classified into three categories. The first is marine algae, the second is echinodermata, and the third is mollusca. Marine algae include Hizikia fusiformis, Gelidium amansii, Eklonia cava, and Undaria pinnatifida; echinodermata includes Apostichopus japonicas and Anthocidaris crassispina; and mollusca has Turbo sazae, Haliotis discus hanai, and Haliotis diversicolor.

These nine biological resources have been major resources for haenyeo for several decades. The nine species live from the sea surface to $25 \mathrm{~m}$ deep, creating an ecological cycle, which is a virtuous cycle of co-prosperity. First of all, Gelidium amansii and Eklonia cava create a habitat for Anthocidaris crassispina, Turbo sazae, Haliotis discus hanai, and Haliotis diversicolor, which feed on Hizikia fusiformis and Undaria pinnatifida and whose excretion is broken down into nutrition for Undaria pinnatifida, Gelidium amansii, and Eklonia cava, among others. Apostichopus japonicas help keep their habitat clean.

Jeju haenyeo have set the period for gathering sea products and controlled fishing activity to help grow and maintain an ecological cycle of their major sea product collection. Jeju haenyeo learned by 
themselves about the prohibition period for gathering folivorous marine resources and marine algae while working in the water, and they have passed down this information from generation to generation.

It is prohibited to catch folivorous marine resources such as Turbo sazae, Haliotis discus hanai, and Haliotis diversicolor during their spawning season (Table 1; the colored cells in the table refer to the non-harvest period). For Turbo sazae, the prohibition period (spawning season) is from June to August. For Haliotis discus hanai, it is from October to December, and for Anthocidaris crassispina, it is from September to October. In the case of Gelidium amansii, Eklonia cava, and Hizikia fusiformis, no prohibited periods have been determined traditionally. Usually, the harvesting period for Apostichopus japonicas is from October to November. Gelidium amansii is collected between April and July. For Hizikia fusiformis, the usual collecting period is from April to May. For Eklonia cava and Undaria pinnatifida, it is from August to September and from May to July, respectively.

Table 1. Compliance with non-harvest seasons.

\begin{tabular}{llll}
\hline \multicolumn{1}{r}{ January } & February March April May June July August September October November December \\
\hline Turbo & & & \\
Sazae & & & \\
Haliotis & & & \\
Discus & & & \\
Hanai & & \\
Apostichopus & & \\
Japonicas & & \\
Haliotis & & \\
Diversicolor & & & \\
Hizikia & & & \\
Fusiform & & & \\
Gelidiun & & & \\
Amansii & & & \\
\hline
\end{tabular}

Along with the non-harvest seasons, Jeju haenyeo strictly adhere to size limits, as well. In particular, they strictly obey the size limits of Turbo sazae, Haliotis discus hanai, and Haliotis diversicolor: they must not catch Turbo sazae smaller than 7 centimeters, Haliotis discus hanai smaller than 10 centimeters, or Haliotis diversicolor smaller than $3.5 \mathrm{~cm}$. The observance of harvest seasons for these sea products was developed by the haenyeo through their efforts to sustain marine biodiversity. In the traditional society, their knowledge about harvesting seasons was learned through their efforts to preserve marine biodiversity over a long history of fishing.

Jeju haenyeo are ecological divers who, taking the sea as their main arena in the "life-world" [13], embed in their life the ecological values based on the sustainable management of agro-biodiversity, which has been inherited through their local and traditional knowledge systems. In other words, the Jeju haenyeo's knowledge systems about the observance of harvest seasons for the sea products is embedded in the realm of the "bodily affect" [14] of haenyeo, not in that of conscious thinking, through the repeated process of unconscious habituation in the life-world.

Knowledge systems about the observance of harvest seasons for the sea products embedded in the realm of the bodily affect of haenyeo mean that they exist as the affect of the Jeju haenyeo through the process of embodiment. That is, the divers learned their local and traditional knowledge systems "with the body", not with the head, through muljil experiences in the sea, the main environment of their livelihood. Here, "what is learned with the body exists as the affect" [15-21] is the key statement for comprehending the implication of the local and traditional knowledge systems of the Jeju haenyeo.

One of the best examples for understanding "learning something with the body, not the head" is learning how to swim. Swimming is not something one learns with their head. It cannot be learned by means of linguistic or visual explanations or lessons. It can only be learned through the body. How to swim is embedded in your body through the "affect of water and your body" that occurs in the performative process of swimming. Eventually, your "body" becomes a unique conduit through which you can learn how to swim.

When swimming, your body reacts to the feeling that your body is slanted, pushed by the heavy current. The reaction is immediately made without undergoing the process of analytic thinking. 
Specifically, learning how to swim, you do not think analytically that the speed of the current is $0.5 \mathrm{~m} / \mathrm{s}$, and the right side of your body is tilted at an angle of $1.23^{\circ}$, so you need to move your arms at the speed of $0.232 \mathrm{~m} / \mathrm{s}$ and your legs at the speed of $0.317 \mathrm{~m} / \mathrm{s}$, while maintaining a lung capacity of no less than $5000 \mathrm{~mL}$ [22].

Without the aforementioned mathematical thinking, knowing how to swim exists as memories accumulated not in your brain but in your body. In other words, it remains as a fingerprint inscribed in your body through the affect about your bodily movement in the water, or the bodily affect [19]. This explains the meaning of the "bodily affect", the core implication of the Jeju haenyeo's local and traditional knowledge for the sustainable management of the agro-biodiversity of sea products [23].

\subsection{Cultures, Value Systems, and Social Organizations}

Considering the fact that Jeju haenyeo have lived in an environment that contains this competitive exclusion principle - that is, an environment in which winners survive and losers fall behind-it can be inferred that the local and traditional knowledge systems for the sustainable management of agro-biodiversity of sea products are maintained amongst Jeju haenyeo. In spite of living in an environment that contains this competitive exclusion principle, the Jeju haenyeo have been able to become ecologists who pay attention to sustainable management for the agro-biodiversity of sea products; the reason for this success can be found in their cultures, value systems, and social organizations, which are manifested as the "liberal communitarianism-based hierarchical tradition" of the Jeju haenyeo.

The social organizations of the Jeju haenyeo are based on the hierarchical tradition of diving haenyeo, divided by their diving skills into sang-goon (the high rank), joong-goon (the middle rank), and ha-goon (the low rank). The connectivity between the hierarchical tradition and the liberalistic aspect of the culture of the Jeju haenyeo is best represented in the divers" "self-ownership", the backbone of liberalism [23]. From the perspective of liberalists, the top priority of a good society is to absolutely ensure that its members enjoy the right of self-ownership [24]. Self-ownership refers to the ownership rights one has over oneself. The term "oneself" here is purely reflexive in its meaning and indicates that the owner and the owned form a single, identical unit [25].

The hierarchical tradition of the Jeju haenyeo has its linkage to the liberalistic concept of "self-ownership" in that the criterion of "personal capability" extrudes that of "age" in deciding the hierarchy (in South Korea, all kinds of social organizations are based on hierarchical relations that are based on age) [26]. Most distinctively, the rank of haenyeo is thoroughly determined according to "the level of experience and skills concerning muljil", not the age of the divers. This means that any highly experienced and skillful diver can advance to the sang-goon rank, even if she is younger than others. Conversely, it is possible that elderly divers are ranked low if they lack experience or skill. Growing old naturally increases the probability that haenyeo will be categorized as sang-goon divers, as they are likely to have accumulated experience and skill. It is obvious, however, that their age is not an absolute criterion for the sang-goon group.

A diver's experience and skill in muljil originate absolutely from her own will and capability. As the Jeju haenyeo decide their ranks according to the level of experience and skill that the diver accumulated through her efforts, the hierarchy implies the "complete guarantee of self-ownership". In the liberalistic context, "it is moral to own only as much as one's personal capability allows and not to take any measure other than one's capability. A good community is a community that consists of those moral agencies that take moral actions" [27].

As proven in the hierarchy of sang-goon, joong-goon, and ha-goon, the Jeju haenyeo thoroughly exclude age from the criteria of their social status; rather, they place their personal capabilities and responsibilities at the center of the constitution and the operation of their community. This traditional hierarchy exactly corresponds to liberalism, which avoids "an attempt to maintain one's status by taking other measures than one's capability and responsibility", as it causes "damage to the unique right bestowed to others" [24]. 
The distinction of the culture of the Jeju haenyeo can be found in the perfect balance of its liberalistic and communitarian values. In other words, the liberalistic values and the communitarian values of the culture are in a complementary relationship with one another in the cyclical architecture of the culture. The mechanism of this perfect balance of values clearly conforms to the communitarian significance hidden in the hierarchy of sang-goon (the high rank), joong-goon (the middle rank), and ha-goon (the low rank).

The previous paragraphs illustrate that the essence of the traditional hierarchy of the Jeju haenyeo lies in its thoroughly liberalistic values that focus on "personal capabilities and responsibilities". Liberalistic values have a paradoxical linkage to the communitarian values when taking the "perspective that the community is the source of the principles of justice". This perspective indicates that the principles of justice as the social standard were established not through non-historical, extrinsic norms but through historical, intrinsic norms.

In the communitarian context, the traditional hierarchy of sang-goon, joong-goon, and ha-goon was created because the divers were aware that the existence of a member who fails to make the utmost efforts to improve her personal skills is nothing more or less than harmful for the entire community. Traditionally, the Jeju haenyeo perceived "the non-exertive incompetent" as risk factors that erode "the shared sense of the common good" [28] in the haenyeo community. The hierarchy of sang-goon, joong-goon, and ha-goon is social proof of the communitarian efforts that the Jeju haenyeo made to minimize the number of "non-exertive incompetent" divers.

The most effective way to motivate the non-exertive incompetent in the community to make improvements is "to impose the sole responsibility on the individuals for the cost of their own choices" [29]. In the haenyeo community, a diver whose incompetence is considered to be due to a lack of effort would never be able to escape the socioeconomic status of ha-goon and would be treated as such. By deciding that the hierarchy within the community depends on the individual capabilities and responsibilities of each individual, the Jeju haenyeo attempt to maintain social tension in the community concerning the possible emergence of non-exertive incompetent members.

As much as they are wary of "effortless incompetent" members, the haenyeo community socially embraces those who may lack abilities but strive to contribute to the community, which is confirmed in gae-sŏk. "Gae-sŏk" refers to the tradition in which divers with larger yields put a certain amount of their catch into the mang-sari (net) of those with smaller yields. Generally, the divers in the sang-goon/joong-goon groups are expected to have larger yields, while those in the ha-goon group tend to have smaller yields.

Haenyeo consider it taboo to perform muljil alone. They always work together with their buddies, under the principle that "no haenyeo dive underwater without a buddy" (Figure 5). In particular, either a sang-goon or a joong-goon diver performs muljil in a pair with a ha-goon diver. When the diver of a higher rank goes underwater, the one with the lower rank stays above the water and learns from the more skilled diver, while keeping an eye out for her safety. This is where the reciprocal duties occur.

The stake of the ha-goon diver, who tends to have a smaller catch, emerges when making efforts to improve her diving skills by learning from the sang-goon or joong-goon diver and when contributing to the safety of the more skilled partner. Accordingly, the higher-ranked diver (sang-goon) is obliged to give a certain portion of her catch to the lower-ranked diver (ha-goon), and at the same time, the lower-ranked diver is obliged to receive it. If either of them neglects their duties of giving or receiving the catch, the diver who neglects the duty will lose her authority [23].

In the communitarian context, gae-sŏk signifies that the community of the Jeju haenyeo is formed on the basis of the virtues of benevolence and solidarity. With the virtue of benevolence, the community forms the mindset of solicitude amongst its members, while the virtue of solidarity helps build a strong bond in the community on the basis of the solicitude of its members for each other. According to Michael Sandel, a communitarian philosopher, members of a community who establish a correlation of the virtues of benevolence and solidarity as a social value voluntarily respond to the needs of other 
people, which springs from their shared goal of benevolence and solidarity. Thus, they need not claim any rights over others [30].

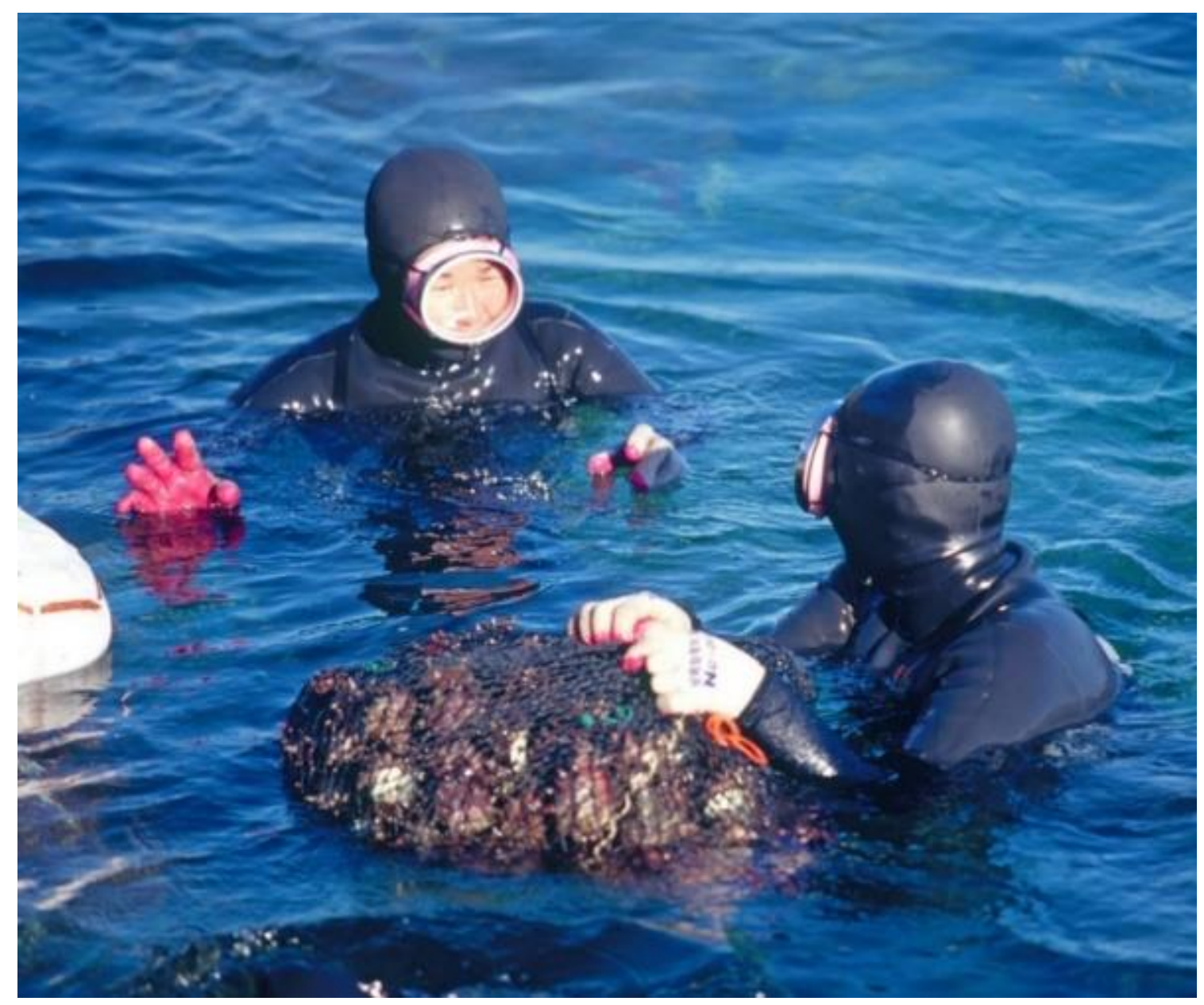

Figure 5. Buddy system of the Jeju haenyeo (Photo: Jeju Haenyeo Museum).

The aforementioned communitarian value exactly coincides with the social mechanism of gae-sŏk. The tradition practiced among the Jeju haenyeo is a cultural agent in which the sang-goon/joong-goon and the ha-goon divers respond voluntarily to the needs of their community; therefore, none of them need to claim their respective rights. This implies that the cultural agent called gae-sŏk represents the public responsibility that the members of the haenyeo community build through the virtue of engaging in the public relationships of muljil, rather than the obligation of the members for each other [31,32].

Another cultural practice that shows communitarian value is the designation of fishing grounds for community wellbeing. Haenyeo on Jeju have designated special fishery zones in their village fishing grounds-the Halmangbadang zone, aegibadang zone, and the public fishing zone. Halmangbadang, located in the intertidal zone, is for elderly haenyeo who no longer dive or gather seafood as well as before, so they can go diving and harvest seafood without much difficulty (Figure 6). Aegibadang, also located in the intertidal zone, is designated for young and new haenyeo who have little or no experience in underwater harvest work. Finally, the public fishing zone is a fishing ground designated for the development of village communities. Profits made from this public fishing zone are used for schools and public programs in the village. The designation of fishing zones for community wellbeing clearly shows that the Jeju haenyeo fisheries are highly linked to communitarian value. 


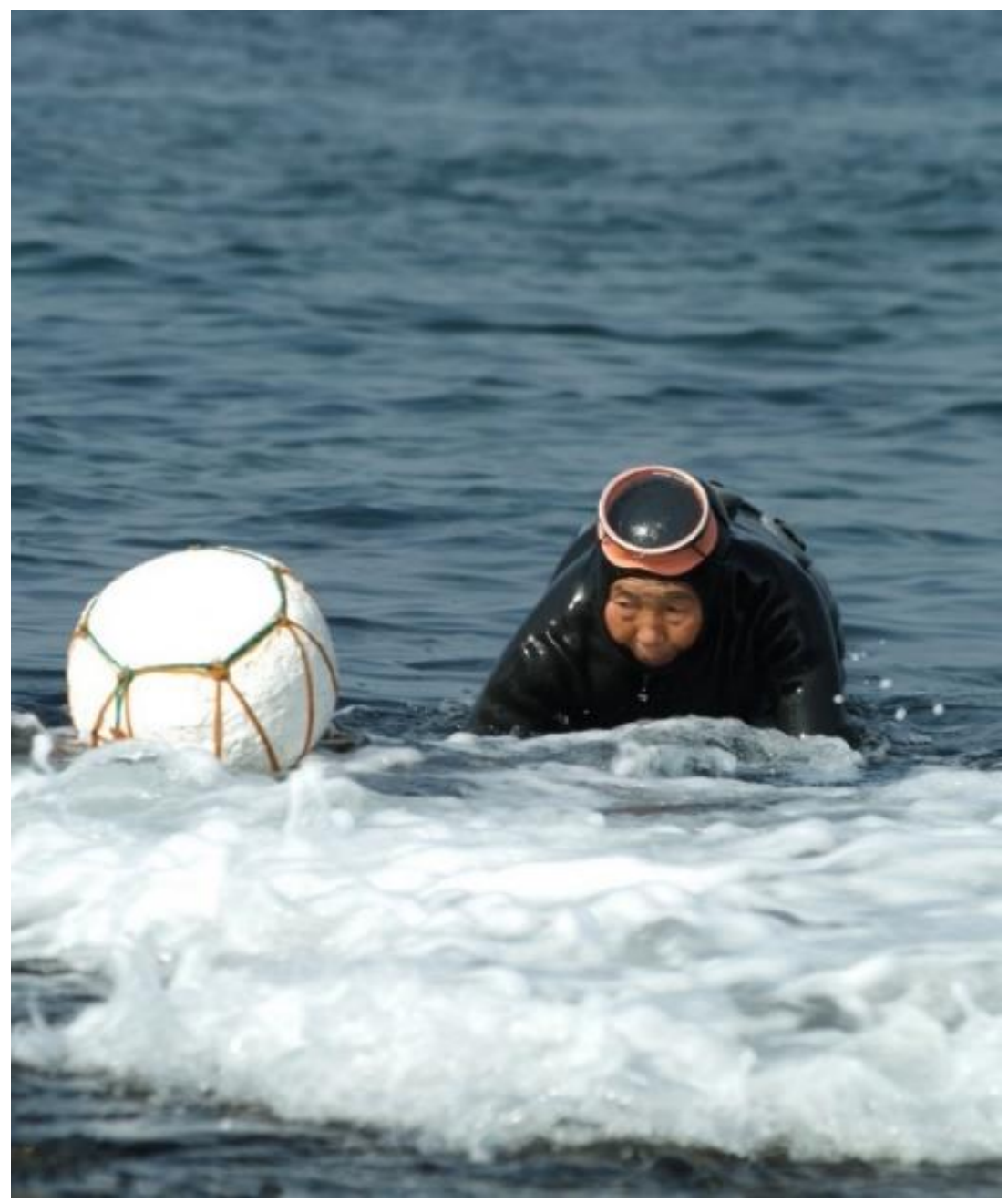

Figure 6. Hal'mang'badang: fishery for the elderly haenyeo (Photo: Jeju Haenyeo Museum).

\subsection{Landscape and Seascape Features}

The cultures, value systems, and social organizations of Jeju haenyeo, which are conceptualized as "liberal communitarianism", are represented through the landscape and seascape features of Jeju haenyeo fisheries. One of the most significant features of the Jeju haenyeo fisheries landscape is the folk housing landscape of the Jeju haenyeo, which is called $A h n^{\prime} g$ ŏ $^{\prime} r i-B a k^{\prime} g \mathrm{gó}^{\prime} r i$ [23]. Traditionally, the folk housings of the Jeju haenyeo basically feature two separate houses built in the same residential areas, surrounded by walls or fences (Figure 7). The house located farthest from the front gate is referred to as " $A h n^{\prime} g$ '̆ $^{\prime} r$ " (the inside unit), while "Bak'gó' $r i$ " (the outside unit) refers to the house built nearest the gate. These buildings are also called "U'nyŏk'gŏ'ri" (the upper unit) and "Ahl'nyŏk'gŏ'ri" (the lower unit), depending on which is located at the highest altitude from the sea (ibid).

The core cultural aspects of the folk housing cultural landscape of the Jeju haenyeo can be categorized into two parts. The first is the completely separate living spaces between families led by the elderly parents and their married son. This means that the two different families maintain their own separate kitchens and live in their respective living spaces based on cooking in a completely independent manner. The second is the swapping of living spaces between families led by the elderly parents and their married son. Once the elderly parents reach the age of retirement, the parents (who

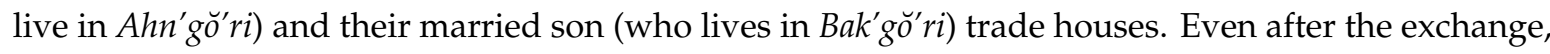
the two families maintain their separate kitchens and live independently in their respective living spaces through completely independent cooking routines. 
Let us look into the first cultural feature of $A h n^{\prime} g \breve{o}^{\prime} r i-B a k^{\prime} g \breve{o}^{\prime} r i$, that is, the completely separate living spaces (Figure 8) between families led by the elderly parents and their married son. "Completely separate living spaces between the families led by the elderly parents and their married son" conforms with the completely independent kitchens/cooking between families led by the elderly parents and their married son. In the local folk culture, the separation of kitchens/cooking means the separation of the lives of women who take responsibility for cooking - that is, the mother of the married son and his wife. The connectivity of this separation from the perspective of cultural ecology can be found in the working hours of the married son's mother and his wife, who are both haenyeo and whose roles change depending on their age.

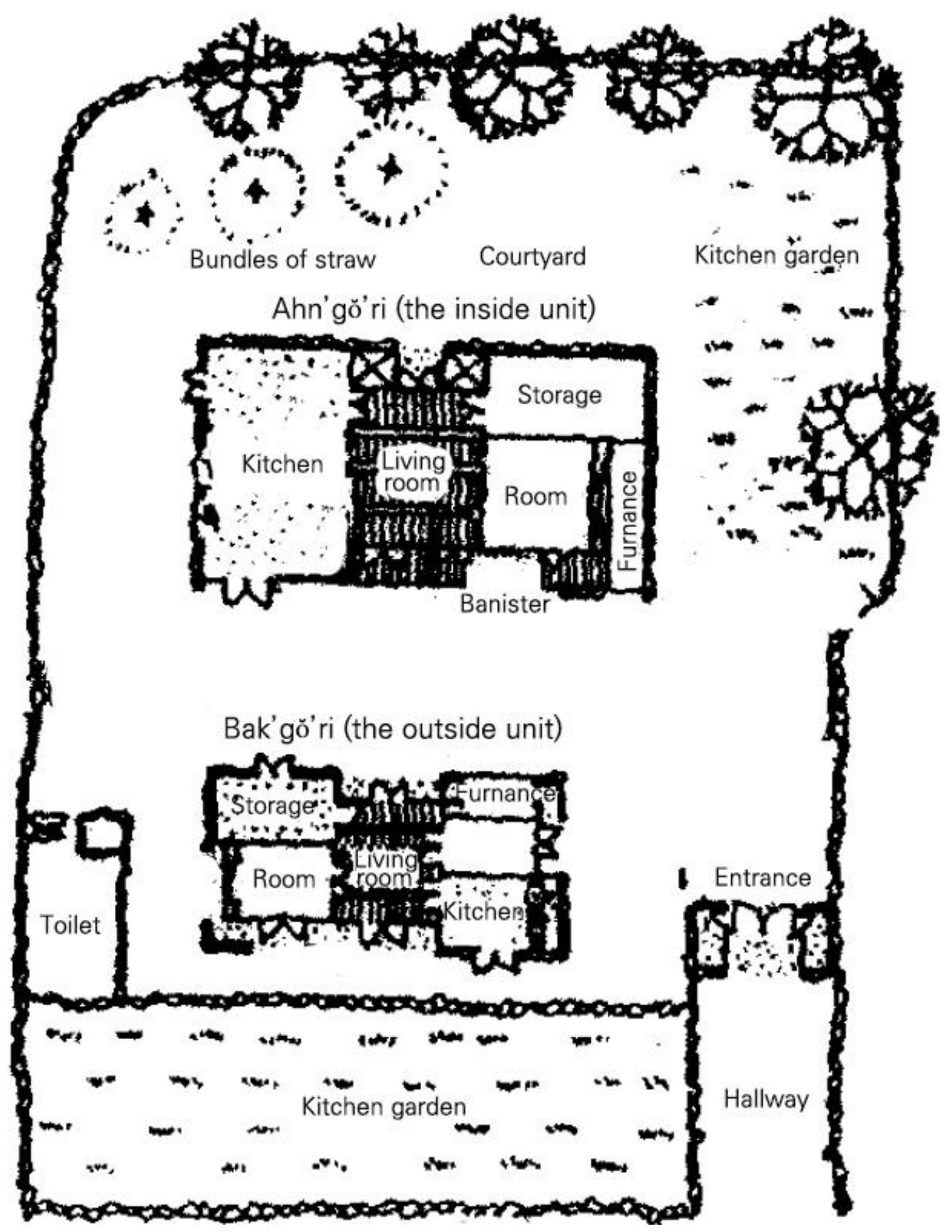

Figure 7. Floor plan of $A h n^{\prime} g$ ŏ $^{\prime} r i-B a k^{\prime} g \mathrm{ou}^{\prime} r i$. 


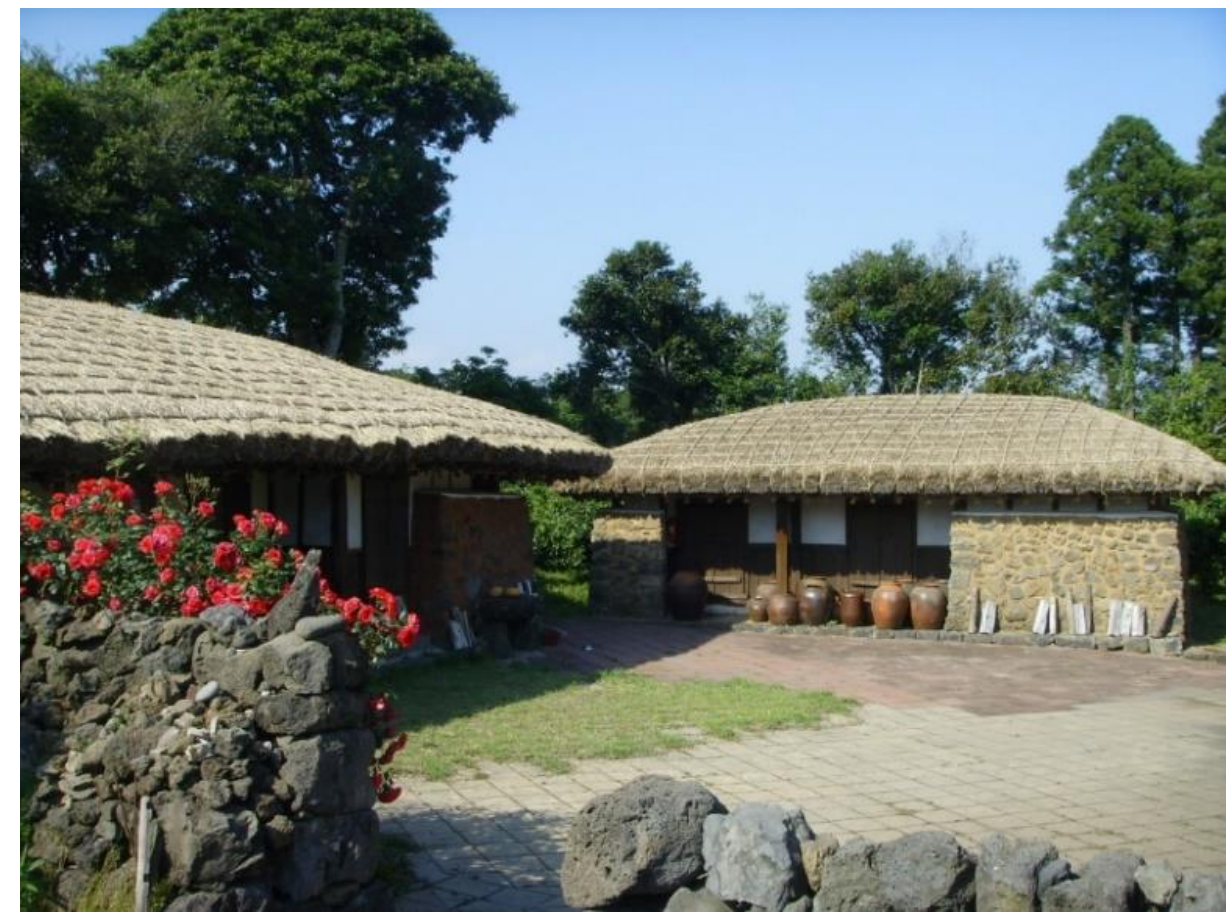

Figure 8. Typical landscape of Ahn'gŏri-Bakgŏ'ri (Photo: Ko, Young-Chul).

Considering the daily rhythms of the Jeju haenyeo, the daily working hours of the mother-in-law and the daughter-in-law vary as the elderly mother falls short of physical strength, while the daughter is capable of vigorously conducting muljil activities. Though unable to perform muljil, the elderly haenyeo, if still capable of basic physical activities, works in the field without exception, while their daughters-in-law work in the sea. This means that young haenyeo who are actively involved in muljil follow their daily working cycles by the multtae (tide time), while their mothers-in-law, who also work in the sea, also tune their working cycles to their personal conditions on the basis of their daily health condition.

The difference in the daily working cycles of the elderly haenyeo and her daughter-in-law (who is also a diver) connotes the fact that they have different cooking cycles. For instance, the mother finishes eating breakfast at 05:00 a.m. and leaves home to work in the field at 06:00 a.m., while her daughter-in-law finishes eating breakfast at 07:00 a.m. and goes to the sea to perform muljil at 08:00 a.m. Under these different cooking schedules, mother divers have traditionally prepared meals for themselves instead of forcing the cooking cycles of their daughters-in-law to fit those of their own. By doing so, the mothers have thoroughly separated the cooking cycles of the two generations.

The precept described above reveals the connectivity between the first cultural feature of $A h n^{\prime} g \mathrm{or}^{\prime} r i-B a k^{\prime} g \mathrm{oó}^{\prime} r i$ (i.e., completely separate living spaces between families led by the elderly parents and their married son) and the Jeju haenyeo's cultural tradition of liberalism. In the local folk society, mothers-in-law earned their livelihood according to their personal capabilities as haenyeo. As they were recognized and allowed opportunities according to their capacities under the competitive exclusion environment, relying on their daughters-in-law for food because of old age did not correspond to their life-long pursuit of "competition and independence".

These women live with the cultural precept of not sharing the location of abalone with anyone, not even with their daughters. They are the pioneers of Jeju's seas who never tell their daughters where they can find abalone, as a way of teaching them to survive. It is improbable that these divers, even when elderly, force their daughters-in-law to adjust their cooking cycles in order to prepare meals for them. In this context, the probability of the first cultural feature of $A h n^{\prime} g \breve{o s}^{\prime} r i-B a k^{\prime} g \breve{g o}^{\prime} r i$ (i.e., completely separate living spaces between families led by the elderly parents and their married 
son) can be found in the working hours of the married son's mother and his wife, who are both haenyeo, whose roles change depending on their age. In other words, living in an environment that features this specific working schedule of haenyeo based on their age eventually led to the Jeju haenyeo's pursuit of the cultural value of liberalism. Further, "its representation in the context of landscape" conforms to the folk housing landscape of Jeju, called $A h n^{\prime} g \mathrm{oo}^{\prime} r i-B a k^{\prime} g^{\prime}{ }^{\prime} r i$.

The second cultural feature of $A h n^{\prime} g \breve{g}^{\prime} r i-B a k^{\prime} g o^{\prime} r i-$ the exchange of living spaces between families led by elderly parents and their married son-is related to the cultural value of communitarianism of the Jeju haenyeo. The significance of this tradition is revealed in the spatio-symbolic hierarchy of the $A h n^{\prime} g o^{\prime} r i-B a k^{\prime} g o^{\prime} r i$. When reviewing the spaces from the perspective of structural anthropology, the aforementioned lifestyle of exchanging living quarters is obviously an inappropriate tradition. In structural anthropology, spaces are not homogeneous and feature qualitative segmentation and directionality [33]. In other words, the inside and the outside are given the meaning of a good space and a bad space, respectively.

In the folk housing landscape of $A h n^{\prime} g^{\prime}{ }^{\prime} r i-B a k^{\prime} g{ }^{\prime} r i$, as mentioned earlier, the houses have different names depending on their location. The house located farthest from the front gate is referred to as 'Ahn'gŏ'ri' (the inside unit), while 'Bak'gŏ' $r i$ ' (the outside unit) refers to the house built nearest to the front gate. These buildings are also called ' $U$ 'nyŏk'gón'ri' (the upper unit) and 'Ahl'nyŏk'gŏ'ri' (the lower unit), depending on which is located at the highest altitude from the sea. That is, Jeju's traditional spatial structure is called 'Ahn'gŏ'ri/U'nyŏk'go'ri-Bak'gŏ'ri/Ahl'nyŏk'gŏ'ri', featuring the 'inside/upper-outside/lower' spatial hierarchy.

In the residential lifestyles of Jeju haenyeo, the 'inside/upper-outside/lower' space exists as a homogeneous space, not as a good or bad space, which experiences no qualitative segmentation or directionality. In this paper, I refer to the phenomenon as the "neutralization of spatio-symbolic hierarchy". The cultural-geographical mechanism of this neutralization in Ahn'gŏ'ri-Bak'gó'ri can be found in the Jeju haenyeo's cultural tradition of pursuing communitarianism.

In the Jeju haenyeo society, the elderly parents pursue a rational lifestyle and values in order to survive in a harsh living environment with the competition exclusiveness principle. They voluntarily downgrade the hierarchy of their living space because they find no reason to reside in $A h n^{\prime} g o^{\prime} r i$, the core household residence with a large living space, particularly when their working hours are shortened as a result of old age and when they are transferring the patriarchal rights to their married son. At this point, the cultural tradition of pursuing communitarianism acquires "social buoyancy".

The elderly parents in the Jeju haenyeo society voluntarily relocate their living space from Ahn'gó' $r i$ to $B a k^{\prime} g{ }^{\prime}{ }^{\prime} r i$ in support of their married son and his family, who should now survive in these harsh living conditions. In this process, the solidarity between the two generations becomes even more solidified, which is processed with the socio-political mechanism called the "ethical dynamics of care" between the elderly parents and their married son's family.

The "solicitude" of the married son and his family in reciprocation for that of the elderly parents is expressed by living with them in the same residential area, not outside their walls, while elevating the status of the elderly parents to "sages" who provide them with knowledge and wisdom about the operation and management of the household. This is the core of the ethical dynamics of care between elderly parents and their married son's family through which the intergenerational solidarity (separate but "not alone") can be further solidified. Moreover, this dynamic is the decisive mechanism of the neutralization of the spatio-symbolic hierarchy in the folk housing landscape of $A h n^{\prime} g o^{\prime} r i-B a k^{\prime} g \mathrm{ou}^{\prime} r i$.

As discussed above, $A h n^{\prime} g o^{\prime} r i-B a k^{\prime} g \breve{o}^{\prime} r i$ can be referred to as a representational mediation of the culture of liberal communitarianism of the Jeju haenyeo, where their daily rhythm for economic activities and their survival strategies in harsh living conditions are interlocked. That is, the representational principle of forming the folk housing landscape is identical to the culture of 'liberal communitarianism' [23]. 


\section{Chain of the Five Values of Jeju Haenyeo Fisheries}

The five main values of the Jeju haenyeo fisheries system are interlocked together through ecological sequences, which are biological foundations engaged in the Jeju haenyeo fisheries system. There are six of these sequences, "each composed of an 'impulse', and associated physiological 'act', and a 'satisfaction' which results from that act" [34]. For example, the impulse of hunger is associated with the act of eating, resulting in satisfaction by "vitalizing with restored energy".

The chain model of the Jeju haenyeo fisheries system (Figure 9) is based on the co-relationship between five basic needs and their respective cultural responses (Table 2). First, the five basic needs are metabolism, ecological stability, knowledge conservation, social stability, and stable reproduction. Second, the cultural responses to those needs are gathering sea products, maintaining agro-biodiversity by using local and traditional knowledge systems, liberal communitarianism, and $A h n^{\prime} g \mathrm{ŏ}^{\prime} r i-B a k^{\prime} g \mathrm{oo}^{\prime} r i$ housing. Finally, each of the cultural responses is relevant to the five main values of GIAHS.

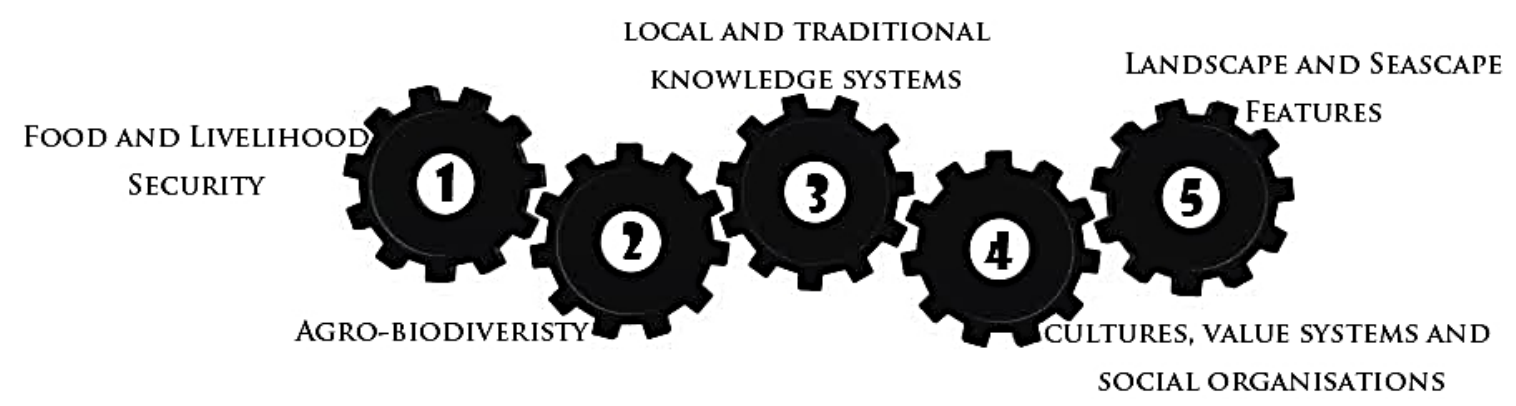

Figure 9. Chain of the five values of the Jeju Haenyeo fisheries system.

Table 2. Five basic needs and their cultural responses in the Jeju haenyeo fisheries system in the context of the Globally Important Agricultural Heritage System (GIAHS).

\begin{tabular}{|c|c|c|c|}
\hline No. & Basic Needs & $\begin{array}{l}\text { Cultural Responses in Jeju } \\
\text { Haenyeo Fisheries System }\end{array}$ & The Five Main Values of GIAHS \\
\hline 1 & Metabolism & Gathering sea products & Food and livelihood security \\
\hline 2 & Ecological stability & Maintaining agro-biodiversity by & Agro-biodiversity \\
\hline 3 & Knowledge conservation & using local and traditional & Local and traditional knowledge systems \\
\hline 4 & Social stability & $\begin{array}{l}\text { knowledge systems } \\
\text { Liberal communitarianism }\end{array}$ & $\begin{array}{c}\text { Cultures, value systems, and social } \\
\text { organizations }\end{array}$ \\
\hline 5 & Stable kinship care & Ahn'gŏ'ri-Bak'gŏ'ri housing & Landscape and seascape features \\
\hline
\end{tabular}

The chain of the five values of the Jeju haenyeo fisheries system has evolved into probable causation amongst the cultural responses that are derived from the basic needs. The essence of probable causation is placed on the fact that socio-cultural values and material culture are responsive to ecological conditions. Jeju haenyeo harvest seafood that comprises nine species for their food and livelihood. The reason that Jeju haenyeo have been able to secure their food and livelihood by gathering marine products over several decades is that these marine products have been supplied stably. The stable supply of marine products is derived from the maintenance of the ecological cycle amongst the nine species.

The agro-biodiversity of the nine species can be maintained through the ecological cycle (Figure 10). The nine species provide shelter and nutrition to each other. Besides this, if a population of a certain species gets too large or small, the ecological cycle is overloaded and cannot maintain symbiotic circulation. Jeju haenyeo already knew this through their own local and traditional knowledge of the non-harvest seasons of the marine products. Following the compliance with non-harvest seasons, Jeju haenyeo have tried to do their best not to interfere with the ecological cycle. 


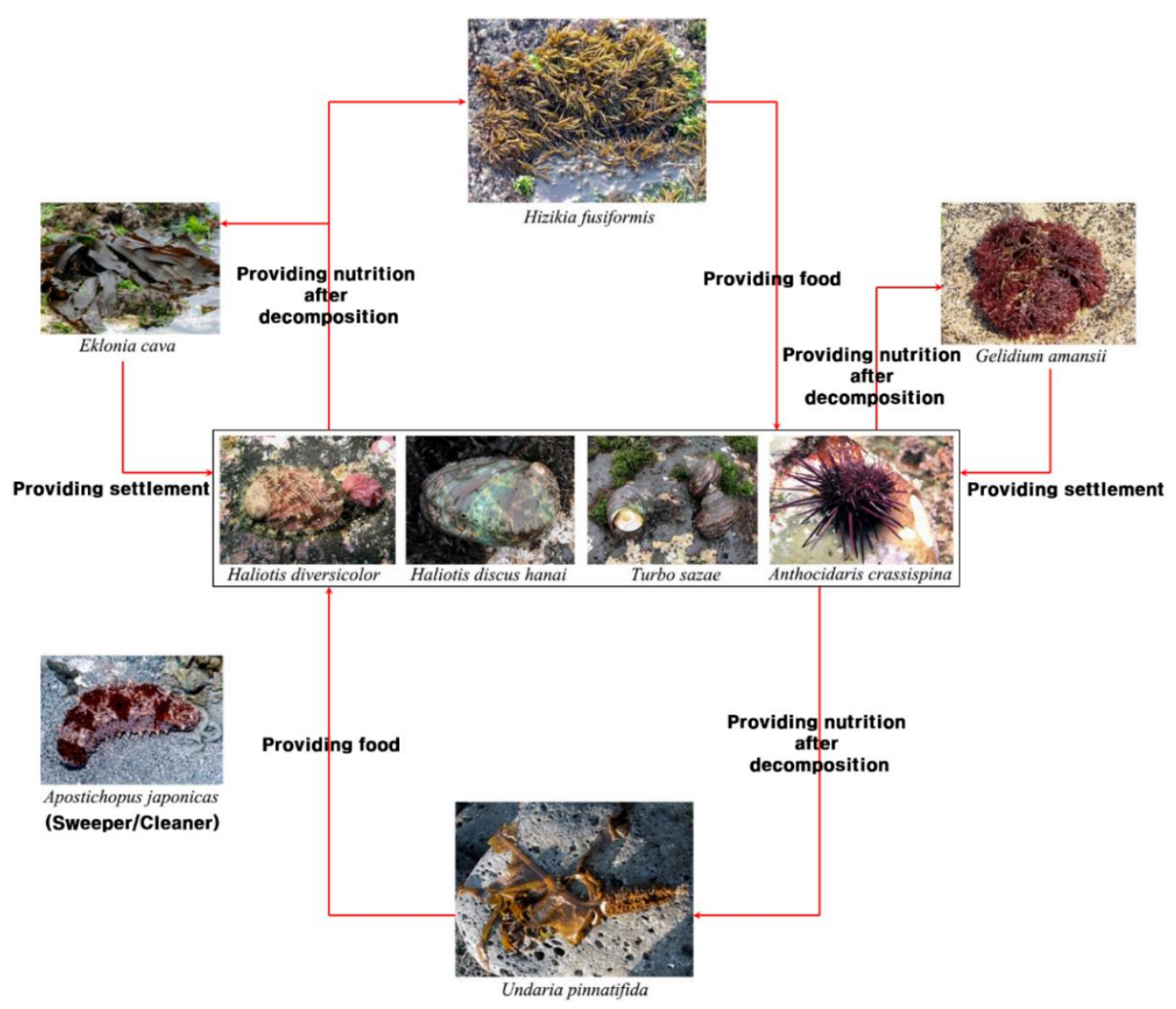

Figure 10. Biodiversity-centered eco-cycle of key marine resources collected by Jeju haenyeo.

This implies that Jeju haenyeo avoid situations that would compel each haenyeo to gather marine products without limit. That is, they avoid "the tragedy of the commons" [7]. The tragedy of the commons refers to "the degradation of the environment to be expected whenever many individuals use a scarce resource in common" [35].

To illustrate the logical structure of his model, Hardin asks the reader to envision a pasture 'open to all'. He then examines the structure of this situation from the perspective of a rational herder. Each herder receives a direct benefit from his own animals and suffers delayed costs from the deterioration of the commons when his and others' cattle overgraze. Each herder is motivated to add more and more animals because he receives the direct benefit of his own animals and bears only a share of the costs resulting from overgrazing (ibid).

Jeju haenyeo never gather an excess of available resources. Here, what should be highlighted is the fact that the local and traditional knowledge of the non-harvest seasons of marine products cannot be a sufficient condition for compliance with non-harvest seasons. Their socio-cultural value, liberal communitarianism, has played the role of the political ground of non-zero-sum games in Jeju haenyeo fisheries.

Zero-sum games, a concept that originated from game theory in economics, are, for example, economic activities in which the winner and the loser are separated through competition, and the winner monopolizes all resources [36]. Although the haenyeo fisheries on Jeju are based on competition, they are not a zero-sum game, but rather a non-zero-sum game. As already demonstrated in Section 2.3, there is a hierarchical order based on diving skills and experience (liberalism aspect), but it is not meant to separate the winner and the loser (communitarianism aspect). 
The intention of the hierarchy is for haenyeo to encourage each other to grasp their level of experience and skills, identify weaknesses, and improve skills. Clear evidence for this is found in the "gae-sŏk" culture. Gae-sŏk is a culture in which haenyeo who gathered much seafood put part of their yield into the mesh of haenyeo who caught little. This practice shows that the Jeju haenyeo fisheries system is not a winner-takes-all economic system but a win-win economic system, where there is no loser.

Without a non-zero-sum game whose political ground is liberal communitarianism, it would be difficult for Jeju haenyeo to comply with non-harvest seasons according to local and traditional knowledge. This implies that local and traditional knowledge systems of non-harvest seasons, through which the maintenance of agro-biodiversity has been guaranteed, and the liberal communitarianism of Jeju haenyeo are connected.

$A h n^{\prime} g \breve{g}^{\prime} r i-B a k^{\prime} g \breve{o g}^{\prime} r i$ housing of Jeju haenyeo is a landscape in which their liberal communitarianism is represented. The landscape of $A h n^{\prime} g o^{\prime} r i-B a k^{\prime} g$ oú $^{\prime} r i$ housing is created by Jeju haenyeo, and the landscape draws its character from the Jeju haenyeo that inhabit it. As Jeju haenyeo live in Ahn'gó'ri-Bak'gó'ri housing, they gradually impose themselves on their landscape of $A h n^{\prime} g o^{\prime} r i-B a k^{\prime} g{ }^{\prime} \prime r i$ housing, modifying and adjusting it as best they can to suit their socio-cultural value-liberal communitarianism. This is a continuous two-way process, a "socio-spatial dialectic" [37], in which Jeju haenyeo create and modify the landscape of $A h n^{\prime} g o^{\prime} r i-B a k^{\prime} g o^{\prime} r i$ housing, while simultaneously being conditioned in multiple ways by the landscape in which they live.

Here, questions of the priority of the landscape of $A h n^{\prime} g o^{\prime} r i-B a k^{\prime} g o^{\prime} r i$ housing or liberal communitarianism are not important at all. The most important thing is the fact that the landscape of $A h n^{\prime} g \breve{o g}^{\prime} r i-B a k^{\prime} g \breve{g}^{\prime} r i$ housing is "the principal interface between culture and nature, the boundary across which the ecological restraints to which human action is subject interact with the principal socio-cultural practices aimed at overcoming or modifying those restraints" [38]. This speaks to the interconnection between the fourth value (cultures, value systems, and social organizations) and the fifth value (landscape and seascape features) of the Jeju haenyeo fisheries system.

\section{Conclusions}

The sustainability of the Jeju haenyeo fisheries system can be achieved by maintaining the system in which the five values are activated as gears of the system (Figure 11). In other words, without fusing the five values into functional sets, the sustainability of the Jeju haenyeo fisheries system cannot be expected to last. Therefore, without a systematic approach to the Jeju haenyeo fisheries, it is quite difficult for local policies on conserving and managing the Jeju haenyeo fisheries to succeed.

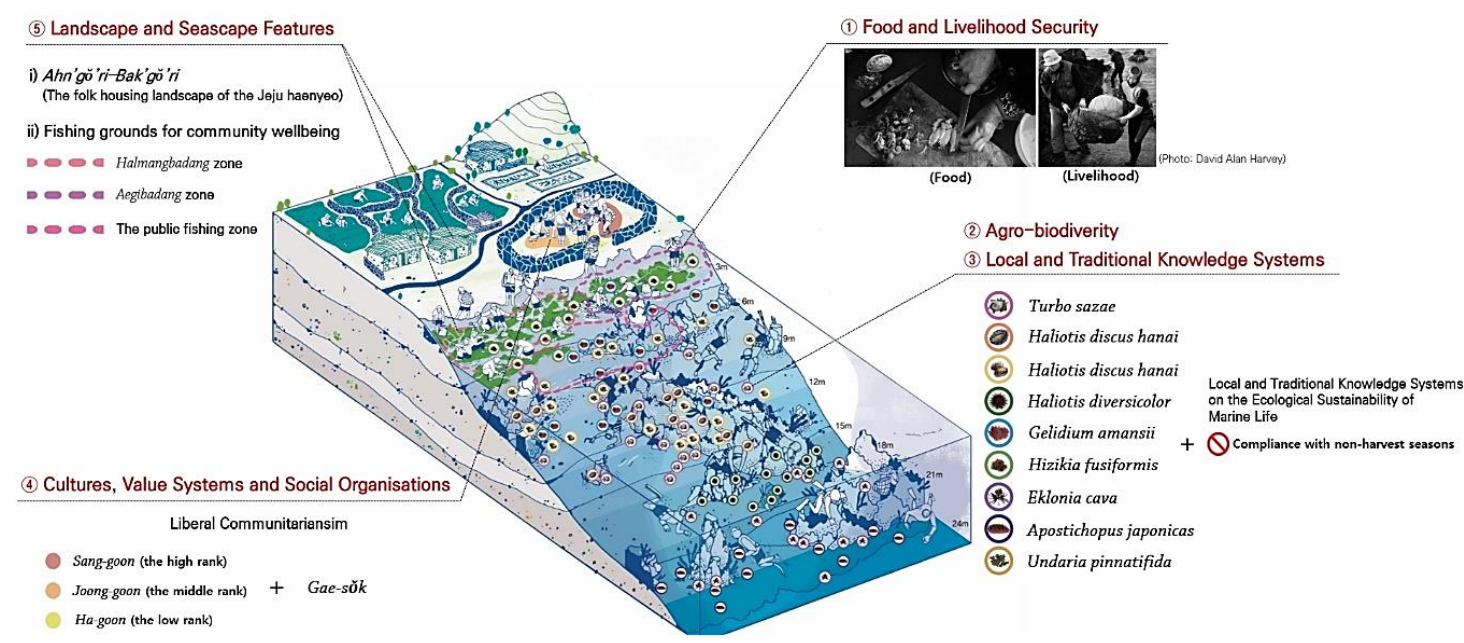

Figure 11. Jeju haenyeo fisheries system in the context of GIAHS (Illustration source: Jeju Special Self-Governing Province; modified by the author). 
Fortunately, it seems that local policies on Jeju haenyeo fisheries have been focused on the maintenance of the chain activation of the five values of the Jeju haenyeo fisheries system. First, focusing on the possibility of a breakdown of the agro-biodiversity, the Jeju Special Governing Province has tried to introduce the TAC (Total Allowance Catch) in the country. The TAC is a catch limit for a sustainable fishery that is set by considering the ecological conditions of marine resources.

A disastrous situation for Turbo sazae happened in 1989. Back then, because of a natural disease in Turbo sazae, the yield of Turbo sazae, which used to be 3600 tons in 1986, plummeted to 440 tons in just three years. The province began implementing the TAC in 1991 to recover the depleted Turbo sazae stock. Thanks to this measure, the average annual production of Turbo sazae has been 2275 tons since the mid-1990s. This is below the average yield recorded in the first half of the 1980s, but it has remained at an adequate level ever since.

Another threat to the sustainability of the Jeju haenyeo fisheries system is the aging population of haenyeo. Ninety-eight percent of haenyeo on Jeju are aged 50 and older. It is a severe threat that the haenyeo population is aging. Another major challenge is that the haenyeo population is declining. In 1965 , the haenyeo population was about 23,000. Now, the number is expected to drop dramatically to fewer than 4000 by 2017 . The province has been running haenyeo schools, vocational schools to increase the population of haenyeo. Among them, Haenyeo School, which opened in 2008, produced over 500 haenyeo by 2017, and about 10 of them joined the local fishing village cooperative and have been working as haenyeo.

Even though the Jeju Special Governing Province has succeeded in maintaining the chain of the five values of the Jeju haenyeo fisheries system until now, the sustainability of the Jeju haenyeo fisheries system in the future can never be guaranteed. The Jeju haenyeo fisheries system is a complex system of interacting quantitative and qualitative components that, together with the chain mechanism for their interaction, constitute an interconnected whole. Complex systems have many unpredictable variables.

No one can predict future problems for the sustainability of the Jeju haenyeo fisheries system. However, it is very clear that future problems cannot be boiled down to one idea or one solution, because the Jeju haenyeo fisheries system is a complex system. Just as the Jeju Special Governing Province responded immediately to current threats (depleting marine resources and an aging population of haenyeo), the local government always tries to make a differential diagnosis of the specific cause of a threat to the Jeju haenyeo fisheries system. This is the only way to guarantee the sustainability of the Jeju haenyeo fisheries system in the future.

Funding: This research received no external funding.

Conflicts of Interest: The author declares no conflict interest.

\section{References}

1. Porritt, J. Capitalism as if the World Matters; Earthscan: London, UK, 2007.

2. Food and Agriculture Organization. Globally Important Agricultural Heirtage Systems (GIAHS) Informational Package; United Nations: New York, NY, USA, 2016.

3. Park, C.-S.; Jwa, H.-K.; Yoo, C.-I. Improvement Plan of Conservation and Management of Jeju Haenyeo Fisheries; Jeju Special Self-Governing Province: Jeju, Korea, 2016.

4. Shin, D.-I. Globalization of Woman Diver Culture and the Plan of Woman Diver Income Increase; Jeju Research Institute: Jeju, Korea, 2011.

5. Yoo, C.-I. Jeju Haenyeo's Diving as the Intangible Cultural Heritage: Sustainable Development and Ecofeminism; Jeju Research Institute: Jeju, Korea, 2006.

6. Geertz, C. The Interpretation of Cultures: Selected Essays; Hutchinson: London, UK, 1975.

7. Hardin, G. The Tragedy of the Commons. Science 1968, 162, 1243-1248. [PubMed]

8. Song, W. Jeju Haenyeo Fisheries System in the Context of GIAHS. In Jeju Haenyeo: A Legacy for the Future; Jeju Special Self-Governing Province: Jeju, Korea, 2018; pp. 118-128.

9. Song, S. The Origin of Culture and its Understanding; Gak: Jeju, Korea, 2019.

10. Takahashi, N. Agricultural Techniques and Farmers of Korean Penninsula; Minsokwon: Seoul, Korea, 1939. 
11. Park, S.-J. Dietary Life of Jeju Haenyeo. In Jeju Haenyeo Fisheries System (GIAHS Application); Jeju Special Self-Governing Province: Jeju, Korea, 2019; pp. 36-45.

12. Heppner, F.H. Professor Farnsworth's Explanations in Biology; McGraw-Hill Publishing Company: London, UK, 1990.

13. Schutz, A.; Lcukman, T. The Structures of the Life-World; Heinemann Educational Books: London, UK, 1974.

14. Pile, S. Emotions and affect in recent human geography. Trans. Inst. Br. Geogr. 2010, 35, 5-20. [CrossRef]

15. Anderson, B. Taking-Place: Non-Representational Theories and Geography; Routledge: London, UK, 2016.

16. Thrift, N. Spatial Formations; SAGE: London, UK, 1996.

17. Thrift, N. From born to made: Technology, biology and space. Trans. Inst. Br. Geogr. 2005, 30, 463-476. [CrossRef]

18. Thrift, N. Space. Theory Cult. Soc. 2006, 23, 139-146. [CrossRef]

19. Thrift, N.J. Non-Representational Theory: Space, Politics, Affect. In International Library of Sociology; Routledge: London, UK, 2008.

20. Thrift, N. Space: The fundamental stuff of geography. In Key Concepts in Geography; SAGE: London, UK, 2009; pp. 86-96.

21. Thrift, N.; Dewsbury, J.-D. Dead geographies-And how to make them live. Environ. Plan. D Soc. Space 2000, 18, 411-432. [CrossRef]

22. Merleau-Ponty, M. The Visible and the Invisible; Northwestern University Press: Evanston, IL, USA, 1968.

23. Song, W. A Semantic Encounter between Representationess and Non-representationess of Landscape: Cultural Geography of Ahn'gŏ'ri-Bak'gŏ'ri, the Folk Housing Landscape of Jeju Island. J. Korean Geogr. Soc. 2019, 54, 229-249.

24. Nozick, R. Anarchy, State, and Utopia; Basic Books: New York, NY, USA, 1974.

25. Cohen, G.A. Self-Ownership, World-Ownership, and Equality. In Justice and Equality: Here and Now; Cornell University Press: New York, NY, USA, 1986; pp. 108-135.

26. Song, W. Localised Modernities: Modernization, Genealogy and Landscape Change in South Korea. Ph.D. Thesis, Queen's University, Belfast, UK, 2017.

27. Waldron, J. Theoretical Foundations of Liberalism. Philos. Q. 1987, 37, 127-150. [CrossRef]

28. Taylor, C. Alternative futures: Legitimacy, identity and alienation in late twentieth century Canada. Const. Citizsh. Soc. Can. 1985, 33, 183-229.

29. Rawls, J. Social Unity and Primary Goods; Cambridge University Press: Cambridge, UK, 1982.

30. Sandel, M. Liberalism and the Limits of Justice; Cambridge University Press: Cambridge, UK, 1982.

31. Kohlberg, L. Essays on Moral Development: The Psychology of Moral Development; Harper \& Row: San Francisco, CA, USA, 1981.

32. Nunner-Winkler, G. Two Moralities? In Morality, Moral Behavior and Moral Development; John Wiley: New York, NY, USA, 1984.

33. Levi-Strauss, C. Tristes Tropiques; Penguin: London, UK, 1992.

34. Malinowski, B. A Scientific Theory of Culture and Other Essays; University of North California Press: Chapel Hill, NC, USA, 1944.

35. Ostrom, E. Governing the Commons: The Evolution of Institutions for Collective Action; Cambridge University Press: Cambridge, UK, 1990; p. 2.

36. Binmore, K. Game Theory; Oxford University Press: Oxford, UK, 2007.

37. Soja, E. The socio-spatial dialectic. Ann. Assoc. Am. Geogr. 1980, 70, 207-225. [CrossRef]

38. Harris, M. Cultural Materialism: The Struggle for a Science of Culture; Random House: New York, NY, USA, $1979 ;$ p. 57.

(C) 2020 by the author. Licensee MDPI, Basel, Switzerland. This article is an open access article distributed under the terms and conditions of the Creative Commons Attribution (CC BY) license (http://creativecommons.org/licenses/by/4.0/). 